\title{
中国古春椎动物化石研究的回顦和成就・
}

\author{
楊 鍾 健
}

（中国科学院古脊椎动物研究所）

\section{一 古督椎动物研究的籍史}

我們的祖先認識到化石的性質, 相且了解它的意 义, 已有一千多年的历史了。把霍椎动物化石当作新 品使用, 为时当更早, 可以迫溯到汉朝时代。但是把化 石作一一門独立的科学——古生物学的研究对象, 当作 研究地史的可靠見歌，以及生物从低等到高等，从简 单到复杂, 推究每称生物的冰龙去脙, 演化过程, 以 至整个生物的㴼变历史, 都还是很新的事, 在欧洲不 过一百多年，在我国也不过几十年的事。古脊椎动物 的研究当然也不例外。

由于中国在解放前是帝国主义㻏略的对鱼, 处于 4殖民地的状态, 所以这一閒科学的研究也自然沾染 上了文化侵略的意味, 直到解放以后, 我們才有可能 作大淠模的独立自主的研究。我們可以把在中国研究 古等惟动物化石的历史分为四个时斯:

第一个时期是 $1846-1916$ 年，也就是外国学者

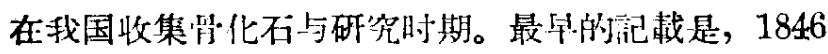
年法尔可酎 (H. D. Falconer) 和考特策(P. T. Cautley）在記述印度西瓦利克化石时即有有关我国西藏 边境骨化石的記載。自此以后, 最重要的为: 英国欧 文关于四川（大約是万县）哺乳动物化石的郡載 (1870)、薂肯关于我国哺乳动物化石的記載 (1885) 和鿭罗塞关于中国哺乳动物化石的研究（發表于 1903 年)。欧文的标本是通过当时在中国的領事收集的，管 肯的标本是德国地質学家李希籍少在我国旅行时从各 地搜集的（主要从衫鋪），舒罗塞的标本是由曾在中国 居住一段时期的哈尔貝尔收集的, 也主要由获鋪收 买。这些朵集品以舒氏搜集得最为丰富, 他一下記避 了 70 多种哺乳动物化石, 几全为新屬新种, 时代大牛 为上新統三趾馬庴, 也有年代較晚的。这些标本, 可 以說部沒有詳确的地点，也十分破碎，仅由牙齿代表， 但是这时期最重要的貢献, 直到現在还有参考价值。

当然在此时期还存其他国人在我国也有發現，如 洛澤在甘肃、青海，老奥布鲁契失在內蒙，內雅宾尼在 黑龙江，都㺕現过脊椎动物化石。而后者是在1904年

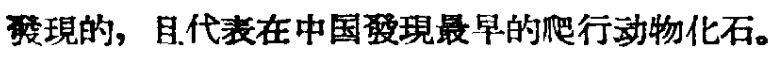

第二个时期可以說是从1916-1927年。在这十多 年中，外国人閒接地在我国搜集材料是汥有了，而代 之直接到我国来做采集与郋掘工作。从形式上講分为 两类，一类是匹馬单槍前来或在我国机关內工作，而 主要是搜集脊椎动物化石，这可以安迭生为代表，他 以中国地質調查所圙問的身份在各地㨨集化石，还拉 来了外国专家师丹斯基等，阔时也披上合作的外衣， 使得侵略面貌不那么明显。此外，如披上傅票外衣的 志华也可列入此类, 他以天津作据点, 曾在华北尔了 大批骨化石分存巴黎和天津（成立了北疆博物館）。另 外一类, 就是外国的一些考察团, 在中国进行大規 模的㡎掘工作。这些考察团名义上無所不包, 实际上 以采集脊椎动物化石为重点工作。他們到中国来, 也不能毫無忌憚、目中無人，所以也与当时的政狩商 妥, 或挂上合作的招牌, 或取得一定的誴解, 泟少在 后期也有些中国人参加工作，作为合作与諒解的象 征。这一項工作最典型的就是美国的中亚考祭团，从 1921年一直进行到1930年, 从我国四川、內蒙, 以及 蒙古人民共和国采获大批脊椎动物化石。其次是瑞典 的中瑞西北科学考祭团，主要在內蒙、甘蔽、青海、 新疆等省做了許多年的工作, 此外还有中法科学考察 团, 但成績不大, 这些考察团的工作实际上在1927年以 后才結束。

第三个时期是从1927年以中国地質調査所名义在 周口店做大規模發崡起到 1949 年全国解放止, 这一时 期的主要标志是我国有了自己的脊椎动物 化石工作 者, 同时, 發㨄工作也大体上在自己的主动計划下执 行。1927年起在周口店的發掘工作由罗氏基金资助， 也由外国人工作，但实际上中国已有人員参加。1928 年成立了新生代研究室, 也就是古脊椎动物研究所的 前身。从此以后也还在国內各地作了不少次的朵集与 考察旅行，搜集了很多的脊椎动物化石。这一时期的 工作还有一个特征, 就是所有化石都留在国內, 不再 象以前全部或大部运到国外陈列。在此时期中，外国 人由合作而到完全退去，中国工作者由栖少数到了有

- 本交为作者于今年11月9日在春梅动场化石保护今 期上所作的报告。 
一定数量, 但还談不到垬展。

第四个时期就是从1949年到現在。这一时期的特 征是, 由于政治上基本上改变了面貌, 科学工作受到 空前的重視。1953年成立了独立的古春椎 动物研 究 室, 1957年文改为所, 研究工作人員由少数人發展到 将近 40 人, 特别是青年干部大量投入这一工作。这时 期另外一个特征是由于地質工作的空前發展, 和广大 人民对文化事業的重視，除了自己研究以外，从这两 方面搜集或揆来的新标本大量赗加，年多一年，也不 难看出解放八年来这門科学的墢展速度远远超过以前

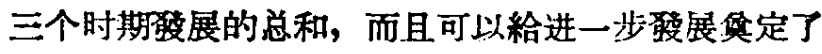
审固的基础。

\section{二 古筒椎动物研究对于地届方面的西献}

外国人在中国做工作的时期，由于化石各牛是間 接搜集或收睛来的，所以对于地层方面貢献不大。但 尽管如此，已可由当时已知的化石判断三趾馬动物群 和較晚的黃土期动物稀的存在。到了第二个时期开始 亲身从地居里采集标本，对于地居上的意义就日谷显 著。現在可以把中国自研究脊椎动物化石以来,对于地 層方面所起的作用由老到新棕合地加以简单的叙迅。

首先談古生代，最早的泥盆䄫魚化石 的现 是 1937年在湖南长沙跳馬澗。以后在云南、广东、湖北 等地也不断有显現，最近在四川重庆、四川江油、江 苏龙潭、浙江杭州也發見古生代后期的魚化石，其中 有二叠紀的魚。这些魚化石对于地畨的㯺 定 很 有帮 助。

在中国，脊椎动物化石在地层时代划分上最起作 用的是关于紅首与紅士等堆积的划分。在这一点上每 个时代都很重要。因为我国自二列紀大陆堆积随时随 地都在增多，因之脊椎动物就覚得和其他化石一样。 可以作地首划分的依据。我国的二叠紀、三叠紀一直 沟有發見答椎动物化石, 而近年以来在新疆奇台、等 远，云南称丰，山西武乡等地区發現了大批的脊椎动 物化石。例如新疆發現的二齿兽、水龙兽、烏魯木齐 兽等动物群, 时代自上二叠紀到下三叠紀, 云南發見 的㯟丰龙、下氏兽等动物群, 时代为上三叠紀晚期, 山西破現的中国肯氏兽和二齿兽等动物群, 时代为下 中三叠粑，由这些化石可以把中国的陆相堆积划分出 来。

侏罗紀、白型紀也含有大量的脊椎动物化石, 特 别是然龙、经魚、龟、魚等化石都發現得很多。所以 这两个时代的地首划分也日漸清楚。在上迌的第一时 期几乎所有化石限于新生代后期。在第二时期，虽然 中亚考察团在內蒙等地發現大量白瑟紀的资椎动物化 石, 可是还沼有什么白瑟粑以前的脊椎呩物化石。在
第三时期与第二时期晚期，除了在各地媵是白望紀、 侏罗紀以前的大量化石外，还㴔現了二叠紀、三叠紀 等时代的化石，所以我們的脊椎动物化石在地屏_l:的 分布也大大增加了。这些化石有时在地居上起决定性 作用，如叮东莱陽等地的地区划分，主要传靠恐龙等

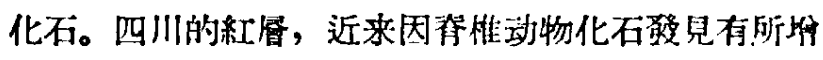
加，所以地屡划分也較以首的确了。什肃的地管山于

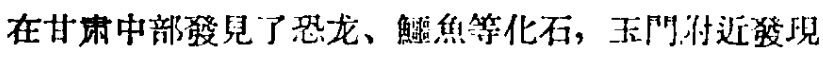
魚、恐龙等化石，对該地区中生代地屡划分也起了作: 用。

新生代初期的地畨划分，几乎完全以脊椎动物化 石为依据。在內蒙古等地即所謂戈壁地区, 为湖相沉 积。在以前，时代不明确。自大量朵集梢椎动物化石 以来，不但發見了許多中生代后期（即上迅的白哇 紀）盆地，还發罗大量的新生代初期主要是古新統到

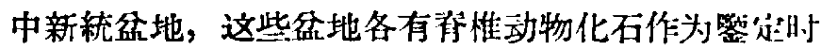
代的指南, 自然以哺乳动物为主, 但也有鱹焦、龟、 泉等化石不少。在其他各省, 第三紀初期的小坡沉积 很多, 化石很少, 时代多不明确。但由于等椎动物化 石研究的加强, 許多地区的地層能照發現的唡椎剙物 化石对年代加以确定。如北京附近的长辛店展, 川西 的垣曲系, 山东的官庄系, 湖南的衡陽居, 广东的笺

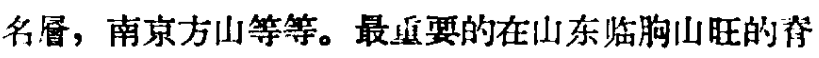
椎动物化石的發現, 确定中国有上中新統, 在甘㴋宁 夏自治州灵武早路芝兽动物群之㡎見, 确定辞区有濑 新統，大大充实了我們新生代地首划分的知識。

最近我們在河南卢氏作了一定限度的弡挸, 絬果 采集了最丰富、保存也相当完好的大量哺乳动物化 石。比以前在蒙古和其他地力所知的更为丰富, 这就 可以对那些地区以及与其他地区地首比較起了更好的 作用。我国西南地区新生代初期化石一问知道很少， 但近来在广西田东, 云南路南等地也發罗了新地点新 材料, 說明拌不亚于华北和其他地区。最重要的是这 些地区的化石，一方面固然和蒙古、华北署的有相 似之处, 有一定关系; 但更重要的还是与印度、糆的 的动物群的密切关系。由这些研究可以进一步与国外 有关的动物群对比，从而在地居上有更大的意义。

新生代后期即上新統, 在以前, 由于脊椎动物化 石研究較早，本来知道一些。以前所說的篦肯、舒罗 塞等的标本, 大部分是由三趾馬紅土中采得的。但战 正地層的研究还是較晚期的事. 由于亲身在山西、随 西、河南, 以及其他地区的采集与覌察, 使我們能把 上新統的土状堆积 (如保德系)、湖状堆积 (如 榆䣥

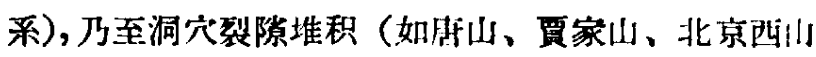
第十八地点等）更进一步地分为上、中、下等畨。当

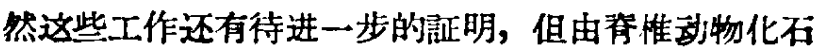


細划分新生代后期地層的可能性是一分步定的。由 最近地質調查表明，在甘肃祁連山山区、青海柴达木 盆地、四川盆地边絯等地区，含有不少脊椎动物化石，

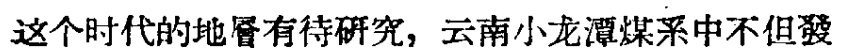
見了森林古猿，还有后期（上新統）地層的存在。

第四紀脊椎动物化石在地蓸上的作用也十分突 H, 就紅色士而言, 除了以前的分析外, 进展不大, 但 湖相堆积象泥河洌时代一类的化石, 在山西临猗有所

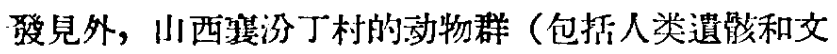
化）好象表示我門以前所謂相当于周口店之上三門系 还有再划分之可能。类似泥河篧的地虽在安徽五河下 草淔有所發見。类似沙拉烏苏的黃土期化石在河南新 祭等地也有郋見, 吉大我們以前的認識。就洞穴堆积 說, 在广西确定了巨猿的产地, 更进一步說明这些地 区的洞穴和周口店一样，包括第四紀乃至第三紀后期 各时代的。可喈我們的工作做的还不多, 化石也不 够, 对于地屏的明确划分和岩相的彼此关系, 目前知 道的还不十分清楚。但进一步研究可以对这些方面有 所貢献, 主要要靠脊椎恸物化石的研究則是然可置疑 的。

以上很粗略地把我国脊椎动物化石和地畨的关系 加以叙迅, 其重要性自然是不言自明, 用不着多說 了。这些化石主要是陆生和淡水生的氽椎动物化石, 但抹不等于說海洋生的金椎动物化石在中国沒有。近 年在湖北襄陽, 貴州兴义 (頎効区大寨) 都發見有海 洋生的爬行动物化石, 海洋的囪类上已逝及, 不必再 筫述, 可見即在海洋区的地層中也一样有脊椎动物化 石。如能加以采集与研究也可与其他化石一样, 对地 㕌答定工作起一定的作用，是毫無疑問的。

\section{三 研究脊椎动物化石在生物学上的面献}

每一个古代生物只要被兒加以研究, 都具有生 物学上的意义, 它有它的来龙去脉、租先兒孙关系, 也有它的同时代的亲屬朋友关系。作为个体㩐是如 此, 作为动物群講也是一样, 不必詳述。下面我只就 我們几十年来关于脊椎动物化石的研究对生物演化等 的意义的最重要的几方面加以电述, 就可以知道其重 整性了。

在魚类方面, 我們的研究还做的不很够, 材料也 很零散。但尽管如此, 对于地理分布、生态关系也有 所收获, 如昌都墢現的西藏硬齿魚, 对与其他大陆的 关系很有意义。三叠紀的魚类化石說明湖水沉积环 境, 汾河和三阴峽等地的青焦化石說 明以介类为食 料, 正与同地舞現的大量厚壳介类相符合, 周口店墢 見的中上新統四川魨焦动物群, 在地理分布上也很有 意义。关于这类工作方在展开, 相信对生物演化方面
还有新的貢触。

两栖类在中国到目前为止誛現很少，除了川旺的 蛙化石較完好外, 多为零碎体骨。这蛙化石連同皮都 保存完好, 同时也有纤虫 (蝌蚪) 的保存, 想見当此 矽藻頁岩沉积时之悠靜环境。

爬行类中在生物学上有意义的墢見很多, 如杯龙 中的前棱蚚, 不但表示在中国首次發見; 而且也表示 与南非酉欧同一类化石比較性的加强。龟类化石材料 甚多, 研究倘少, 但近年来对甘肃与山东白型約龟之 研究, 加强了地理分布方面的了解。解焦化石中以在 四川發見的西蜀鰛, 最为特殊, 与南美第三紀初期者 相似，似有世界性的分布，也代表特殊的一个亚目。 蚚蜴类在內蒙和山西垣曲也有所發見, 填补了这一种

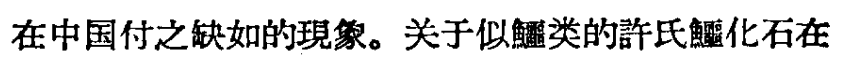
祿丰的材料虽然破碎，但也有一定意义。扭龙类和付 龙在中国發見也不多, 而意义甚大。恐龙类化石在中 国發見最多, 然大牛不完全, 其中以程丰的蚚比类、原 脚类等是最为丰富, 与南非的同时代的各动物群几 乎可以屬与屬相比, 保存也十分好, 是我們脊椎动物 化石在我国最丰富的一个动物群。关于鳥龙类近来在 山东萊陽也做了采統的發拥工作, 特别是鹚鴜咀龙和 青島龙（也就是鴨咀龙科）在生物学上有一定的密 义。除了恐龙以外, 还有毁龙类, 最特别的就是下氏 兽, 代表一种近于哺乳动物的爬行动物。

类似哺乳动物的爬行动物除了上迅的燝龙以外， 还有二选兽、水龙兽、中国肯氏兽、烏瀂木齐兽等动 物群在新疆、山西也均有發現, 而且都十分丰富。这 些动物本身就具有演化上的意义。由于这些門类的设 現, 粰过仔細研究必然对系統分类演化等方面都有所 闻明，可以說是毫無疑义的。

关于鳥类化石的研究在中国可以說还是一个空白 点。但是解放以后, 躳鳥蛋化石的發現日有堵加, 这 說明我国第四紀气候的变化还是十分突出的。

哺乳动物方面, 在中国研究最早, 收获也最大, 中国古生物志中以及其他脊椎动物化石諭文大牛都是 关于哺乳动物的。从門类講, 除了少数特別的門类, 如海生脊椎动物（海狗、海牛等）和照理未登見于旧 大陆（如南美有䠉兽等）外, 可以說所有門类在中国 均有㚇見。特別值得指出的是, 在过去几十年中, 在 亚洲各地（蒙古、东三省）發見了若干有意思的中生 代哺乳动物。

中国第三紀初期的哺乳动物, 虽然到現在还以內 蒙及其邻近地区知道的較多, 但近来在其他地方特別 是垣曲、卢氏等地作了新的發掘, 其中有不少化石在 生物演化上和地理分布上有重大意义。

第三紀后期的哺乳动物特別三趾，馬动物群，静乐 
系的化石，以及第四紀初期的泥河暂动物群，由于材 料經过大規模采集和研究，有許多門类如琶齿类中各 甽第，例如田鼠可以从原始的有根的种类追踪到近代 种类。河狸也有相似的發展。肉食动物中狂、熊、

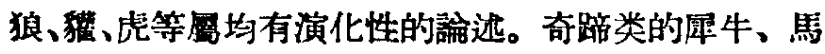
等, 不但可以知道这一时期的彼此关系, 而且可以追 溯到第三紀初期相关种类，偶踠类的材料更为丰富， 地有同样的收获。像类化石在中国酸現的很多, 虽然 －还汥有把新的材料加以系統的研究，但已知材料也可 以說能修訂許多以前关于演化与分布的看法。灵长类 化石不多，但最近在垣曲發見了新的黃河猴标本，在 云南發現森林古猿化石，对于这一屬的新的分布与构 造有了新的見解。多年連地点不明的步氏E猿近年来

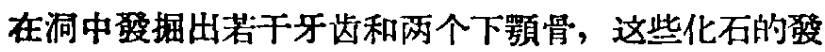
見不但大大地增长了我們关于灵长类的知識, 而且对 人类演化問題也起了很重要的作用。

在人类化石方面，尽管解放以后不到 10 年，而我 們也發現了”很重要的人化石, 首先是資陽人的發現, 可以說是在稪岭以南第一次贞正人类化石的發見。在

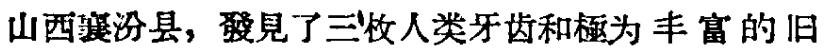
石器。在广西除了發見上迌的巨猿以外, 也有較新的 人化石的弡見，此外在許多地区發見了大批的旧石 呿, 內蒙也現了可与河套人相比的人化石和石器。 所有这些材料都祉明我們認为中国是一个人类化 石丰富的地区的看法是正确的。

由于过去对中国猿人、山頂洞人的發見和研究， 再加上近年来新的标本的發現，使我們能够把猿人、 古人、员人三时代的人都能在我国有所証明。再加上 丰富的石器文化等, 使我們对于我国第四紀关于人类 化石的知識相当的完备。因而在提家与普及这一方面 的科学方面起着卓絕的作用。

\section{四 新中国研究春椎动物化石的展望}

以上擇要說明了我国研究古资椎动物化石的經过 和它在地昼学上及生物学上的意义, 这說明了这一門 科学正同其他科学一样有它的实用上和理 諭上的价 值。

但这是不是說我們对于这一門科学已有了相当的 基础，或者說因有一些成績而感到自滿了呢? 我看完 全不可以，我們的任务十分繁重，我們的工作剛才开 始，無数的新發見还在等着我門。
中国是一个广大的国家，有許多地方，占生物学 家足迹还末到。即使是已知湴一些地区, 虽然含有化 石, 但不过是偶尔經过作了一些采集, 或只有个别的 較大規模的采集, . 但紹不能說尔得很矽。就我倐工作 了几十年的周口店来說, 还有許多东西待發現, 我們 过去工作过的程丰，已有近二十年未作大規模的新的 采集, 其他地大多如此。另外一方面, 地筫普宵工作 日益开展, 也需要化石方面的証据, 所以欲我狮的任: 务重, 工作㴊才开始。

中国脊椎动物化石面临着两个些重的破坏的猫 况。一个是天然的破坏, 那就是由于水土保持工作做 的不好, 氛天有大量的化石被風化被冲㑬而成为灰暨 泥沙流入河海。但这一方面的危害性在不久的未来就 可大为改覌，因为我国的水土保持工作日益展形，而 且局部已收大效。少数不易做水土保持工作和沙漠地 区，就須要經常的有人去采集化石，否則还是会被白 然破坏的。

另一个被破坏的情况就是我椚多少年来傅統的把 骨化石，特别是第三紀后期的，当作剥材使用，稫:住: 不知有多少富有地省学与生物学意义的化石就这样的 被破坏了。因朵集不得法和胃格不固定, 因而尽管需 用量不大，而被破坏的面却很广，因为他們一方面朵 集不擇地点，任意發掘; 另一方面把老的或新的化石 也当作可用的彩用龙骨而發㨄了。这就是这一次开座 談会的意义，希望能有个較要当的协法。

从学术方面看, 以上所述的已知的有名化石的渵 位, 和已知的各門类方面所取得的結論, 紹大部分还 是初步的，不够全面的。本来古生物学是一个以破破 材料的积累为对象的科学,材料一般的不完奎, 但經过 楥常的不解的野外采集和空內研究，終究可以把这門

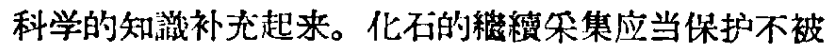
破坏的意义就在于此。它不是象取矿样的办法取一些 就够了，化石永远不能感敩够，今天对氞:一个动物也 許只知道一个牙，象 1903 年舒罗寒所指比那一“猿人 牙”，但几十年之后，許多人头骨、牙齿和四䁌剈·都 可以知道了。

因此我們涩怀信心，还有無数的重要的脊椎动物

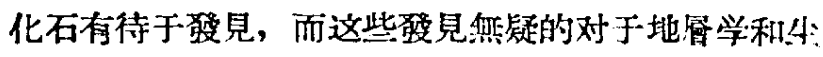
物学将更有重大的貢解, 而对古等椎动物学本场也得 到进一步的發掦。 